\title{
Evaluation of a Sepsis Teaching Rounds Simulation for Pharmacy Students
}

Zach Jenkins

Cedarville University, zjenkins@cedarville.edu

Emily Laswell

Cedarville University, emlaswell@cedarville.edu

Nicole K. Stute

Cedarville University, nstute@cedarville.edu

Follow this and additional works at: https://digitalcommons.cedarville.edu/

pharmacy_practice_publications

Part of the Higher Education Commons, Medical Education Commons, and the Pharmacy and Pharmaceutical Sciences Commons

\section{Recommended Citation}

Jenkins, Zach; Laswell, Emily; and Stute, Nicole K., "Evaluation of a Sepsis Teaching Rounds Simulation for Pharmacy Students" (2019). Pharmacy Practice Faculty Publications. 385.

https://digitalcommons.cedarville.edu/pharmacy_practice_publications/385

This Article is brought to you for free and open access by DigitalCommons@Cedarville, a service of the Centennial Library. It has been accepted for inclusion in Pharmacy

Practice Faculty Publications by an authorized

administrator of DigitalCommons@Cedarville. For more information, please contact

digitalcommons@cedarville.edu. 
Experiences in Teaching and Learning

\title{
Evaluation of a sepsis teaching rounds simulation for pharmacy students
}

\author{
Zachary Jenkins*, Emily Laswell, Nicole Stute \\ Cedarville University School of Pharmacy, 251 N. Main St., Cedarville, OH, United States
}

\section{A R T I C L E I N F O}

\section{Keywords:}

Sepsis

Student perceptions

Simulation

Pharmacy students

Teaching rounds

Pharmacy

\begin{abstract}
A B S T R A C T
Background and purpose: The goal of this prospective, observational cohort study was to determine if simulated interdisciplinary teaching rounds improved student perceptions of confidence and attitudes towards working as part of a team. The secondary objective of this study was to investigate changes in student knowledge of the management of sepsis.

Educational activity and setting: Students participated in a traditional sepsis lecture followed by a simulated interdisciplinary rounding experience. Confidence and collaborative attitudes were assessed using a 5-point Likert scale ( $1=$ strongly disagree, $5=$ strongly agree). Changes in knowledge were measured using multiple choice questions. Students completed these tools at three points in time: pre-lecture, post-lecture, and post-simulation.

Findings: Student confidence and attitudes related to interdisciplinary rounds improved following the simulation ( 2 of 4 items, $p=0.003 ; 2$ of 5 items, $p<0.05$ ). Also, most students agreed or strongly-agreed that the simulation reinforced knowledge gained from lecture (94.7\%), that lecture followed by a simulation was the most effective way to learn about sepsis (94.7\%), and that the simulation helped reinforce critical-thinking skills (94.7\%). Knowledge improved between the didactic lecture and the simulation, but these differences were not found to be statistically significant.

Summary: A simulated interdisciplinary rounding experience may increase student confidence during teaching rounds and improve attitudes towards working alongside other healthcare professionals. Incorporating rounding simulations into pharmacy curricula may be beneficial towards student success on rounds.
\end{abstract}

\section{Background and purpose}

With their expanding role, pharmacists are becoming more involved in direct patient care that often includes interdisciplinary rounding. Some student pharmacists may not have the chance to interact in a formal patient care rounding experience until their advanced pharmacy practice experiences (APPEs) or after graduation. It is important to expose students to these team dynamics so that they are prepared to function in various practice settings. There are many ways in which interprofessional communication can be introduced and strengthened within pharmacy curricula; simulation training is one such method. Simulated clinical scenarios allow participants to discover their roles and responsibilities as part of a healthcare team. These scenarios mimic the high-risk situations encountered in clinical practice and provide a safe haven for students to make and learn from their mistakes. ${ }^{1-3}$

Because sepsis is associated with high mortality rates and is the most expensive condition treated in United States hospitals, it is

\footnotetext{
* Corresponding author.

E-mail addresses: zjenkins@cedarville.edu (Z. Jenkins), emlaswell@cedarville.edu (E. Laswell), nstute@cedarville.edu (N. Stute).
} 
important for student pharmacists to be prepared to interact with other healthcare professionals with respect to the appropriate treatment of sepsis. ${ }^{4-7}$ As such, a simulated sepsis rounding activity could be beneficial for pharmacy student learning.

Current literature appears to support the use of clinical simulations in strengthening pharmacy student confidence. In 2011, Shrader et al. ${ }^{8}$ implemented a simulated interprofessional rounding experience in order to assess interprofessional attitudes as well as self-perceived clinical confidence. Following the rounding experience, self-perceived clinical confidence improved. In 2015, Bingham et al. ${ }^{9}$ conducted a study to evaluate the impact of high-fidelity simulation training on pharmacy student knowledge and skills in Advanced Cardiovascular Life Support (ACLS). Student teams who had previous simulation training demonstrated increased knowledge and skills over teams without previous training for $75 \%$ of ACLS skills observed. In 2018 , Serag-Bolos et al. ${ }^{10}$ evaluated the impact of an oncology simulation on the knowledge and perceptions of 109 pharmacy students using a 5-point Likert scale ( 5 = strongly agree; 1 = strongly disagree). The authors found an increase in student knowledge as well as improvements in perceptions of roles/responsibilities and self-confidence.

In addition to improving student confidence, simulation training has also demonstrated the ability to promote increases in student knowledge. In 2017, Serag-Bolos et al. ${ }^{11}$ evaluated changes in student knowledge regarding pharmacist roles and responsibilities in transitions of care environments using simulation. Although not statistically significant, students demonstrated an overall increase in knowledge following the simulation activity. In 2018, Frenzel et al. ${ }^{12}$ investigated the use of simulations in preparing pharmacy students to identify and respond to medication errors. Following the simulation, students $(n=90)$ showed a statistically significant increase in overall knowledge assessment scores $(p<0.01)$.

To our knowledge, there is minimal literature that describes the relationship between simulated interdisciplinary rounding experiences and changes in clinical knowledge and confidence among pharmacy students when communicating with a medical team. Allowing students to participate in a simulated sepsis interdisciplinary rounding activity may increase student confidence when working as part of a team. This research aimed to investigate the potential benefits of a simulated interdisciplinary rounding experience on student perceptions of confidence and attitudes.

\section{Educational activity and setting}

\section{Simulation design}

Faculty designed a simulated interprofessional rounding activity. Second-year pharmacy graduate students enrolled in an infectious disease course were required to participate in a didactic sepsis lecture followed by a mock interdisciplinary sepsis simulation. Students were provided with an overview of the activity schedule in advance of the simulation (Fig. 1). Patient case materials were made available to the students for use in preparation $72 \mathrm{~h}$ in advance of the simulation. Participating students were expected to complete required readings, review the preliminary case vignette, and prepare a preliminary treatment plan prior to the simulation orientation. During the orientation phase, each student group was informed that they could be asked questions by the mock medical team and would be expected to present their treatment recommendation as part of rounds. Each group of students was then provided with patient information that was not initially disclosed to them in advance of the simulation. This was done to mimic the dynamic nature of electronic medical records. Groups were then allotted seven min to further develop or modify a therapeutic recommendation to present during the simulated rounding experience. Following this, students met with a mock medical team in the high-fidelity simulation center. The mock medical team consisted of faculty and pharmacy resident actors playing the roles of a pharmacist preceptor, attending physician, and medical resident. After the patient was presented to the team, the attending physician and pharmacist preceptor emphasized key teaching points related to sepsis, urinary tract infections, and antibiotic selection as part of the discussion during rounds. Students were expected to provide recommendations directly to the attending physician at appropriate times regarding antibiotic selection and treatment decisions. At the conclusion of the simulation, the students met with the pharmacist preceptor who provided feedback on their performance and highlighted major teaching points of the activity. Facilitator guides were provided to maintain debriefing consistency between groups. The research project was reviewed and approved by the Cedarville University Institutional Review Board.

\section{Survey design and administration}

Students were administered three surveys throughout the activity that were designed to measure changes in both student perceptions and knowledge. The surveys were given to students before the sepsis lecture, after the lecture, and after the simulation. Each survey included five sepsis knowledge-based questions. Knowledge questions remained the same between the surveys administered before and after the didactic lecture. Separate knowledge questions were developed for the post-simulation survey to minimize bias. In order to compare knowledge questions between surveys, each knowledge question was mapped to five domains of sepsis management: (1) patient presentation, (2) patient evaluation, (3) goals of care, (4) antibiotic selection, and (5) antibiotic timing. These domains were identified/generated by the researchers from the 2016 sepsis guidelines. Surveys were reviewed by a faculty member outside of the research project for content validity. The pre-lecture and post-simulation survey also included nine questions to measure student perceptions of confidence levels and attitudes towards teaching rounds. Additionally, a student evaluation of the simulation activity was added to the post-simulation survey to allow for quality improvement of the activity.

All students who indicated consent were included in this study. Students were excluded from the study if they indicated previous exposure to teaching rounds. 


\begin{tabular}{|c|c|c|c|}
\hline Event & $\begin{array}{l}\text { Study } \\
\text { Day }\end{array}$ & $\begin{array}{l}\text { Duration } \\
(\mathrm{min})\end{array}$ & Comments \\
\hline $\begin{array}{l}\text { Pre-Lecture } \\
\text { Survey } \\
\text { Distributed }\end{array}$ & 1 & 10 & \\
\hline $\begin{array}{l}\text { Sepsis } \\
\text { Didactic } \\
\text { Lecture }\end{array}$ & 1 & 120 & \\
\hline $\begin{array}{l}\text { Post- } \\
\text { Lecture } \\
\text { Survey } \\
\text { Distributed }\end{array}$ & 1 & 10 & \\
\hline $\begin{array}{l}\text { Case } \\
\text { Vignette } \\
\text { Distributed }\end{array}$ & 1 & --- & $\begin{array}{l}\text { Students provided with case vignette } 72 \mathrm{~h} \text { in advance of the } \\
\text { simulation }\end{array}$ \\
\hline $\begin{array}{l}\text { Orientation } \\
\text { Phase } \\
\text { (Simulation) }\end{array}$ & 3 & 3 & $\begin{array}{l}\text { Simulation schedule reviewed; students briefed on their role in } \\
\text { the simulation and provided with opportunity to ask questions }\end{array}$ \\
\hline $\begin{array}{l}\text { Preparation } \\
\text { Phase } \\
\text { (Simulation) }\end{array}$ & 3 & 7 & $\begin{array}{l}\text { Students provided with new information for patient } \\
\text { case and given access to copies of select reference books; } \\
\text { students reviewed information and modified therapeutic plan } \\
\text { as needed }\end{array}$ \\
\hline $\begin{array}{l}\text { Rounding } \\
\text { Phase } \\
\text { (Simulation) }\end{array}$ & 3 & 10 & $\begin{array}{l}\text { Students answered "teaching rounds" questions and } \\
\text { provided a therapeutic recommendation to the mock } \\
\text { medical team }\end{array}$ \\
\hline $\begin{array}{l}\text { Debriefing } \\
\text { Phase } \\
\text { (Simulation) }\end{array}$ & 3 & 5 & $\begin{array}{l}\text { Faculty who worked with students as the mock preceptor } \\
\text { debriefed team on performance; faculty clarified knowledge } \\
\text { gaps in sepsis management for student groups when } \\
\text { warranted }\end{array}$ \\
\hline
\end{tabular}

Fig. 1. Simulation and study design.

\section{Statistical analysis}

Surveys and knowledge questionnaires were administered electronically through Qualtrics. ${ }^{13}$ All statistical analyses were analyzed with SPSS. ${ }^{14}$ A confidence level of $95 \%$ was selected to detect statistical significance. Wilcoxon Signed-Rank, McNemar, and paired sample $t$-tests were used to analyze the data where appropriate. Pre-lecture and post-simulation surveys were compared to assess changes in confidence and attitudes; pre-lecture and post-simulation surveys were assessed for changes in knowledge.

Findings

Twenty-three students elected to participate in the study, resulting in a 49\% response rate. Ultimately, four students were excluded due to previous teaching rounds experience. Baseline characteristics revealed that students were more likely to be Caucasian females between the ages of 23 to 25 .

\section{Changes in student confidence}

Before the simulation, students felt uncomfortable or very uncomfortable being asked medical questions when answers were expected immediately $(78.9 \% ; n=15)$ and when making therapeutic recommendations for patients with sepsis $(68.4 \%$; $n=13)$. All students indicated that it is important to be able to work alongside other healthcare professionals and that interdisciplinary teams are beneficial for patients (Table 1). Following the simulation, 26.3\% $(n=5)$ of students remained uncomfortable when being asked medical questions on the spot $(p=0.003)$ but only $10.5 \%(n=2)$ of students were uncomfortable making recommendations 





Table 2

Changes in pharmacy student knowledge.

\begin{tabular}{|c|c|c|c|}
\hline Sepsis management domain & Pre-lecture to post-lecture ( $p$ value) & Pre-lecture to post-simulation ( $p$ value) & Post-lecture to post-simulation ( $p$ value) \\
\hline Patient presentation & 1.000 & 1.000 & 1.000 \\
\hline Patient Evaluation & 0.001 & 0.000 & 0.500 \\
\hline Goals of Care & 0.012 & 0.000 & 0.250 \\
\hline Antibiotic Selection & 0.001 & 0.001 & 1.000 \\
\hline Antibiotic Timing & 1.000 & 0.180 & 0.227 \\
\hline Overall knowledge changes & 0.000 & 0.000 & 1.000 \\
\hline
\end{tabular}

$(p=0.003)$ (Table 1$)$

\section{Changes in student knowledge}

Changes in knowledge were assessed using paired $t$-tests (Table 2). There was a statistically significant change in the overall knowledge outcomes from pre-lecture to post-lecture and pre-lecture to post-simulation $(p<0.001)$. However, no statistically significant changes occurred between the post-lecture and post-simulation knowledge outcomes.

\section{Student evaluations of the simulation}

On review of the simulation, students agreed that it helped reinforce what they had previously learned about sepsis from the didactic lecture $(94.7 \% ; n=18)$. They also believed that a lecture followed by a simulation was their preferred way to learn about sepsis $(94.7 \% ; n=18)$. Finally, students agreed that the simulation helped develop their critical thinking skills and improved their confidence in their ability to interact with others as part of a healthcare team (Table 3). These results were obtained for quality improvement purposes and were not utilized for any statistical comparison.

\section{Discussion}

The Accreditation Council for Pharmacy Education places great emphasis on the important role of interprofessional education in pharmacy curricula. ${ }^{15}$ Notably, Standard 11 explicitly addresses interprofessional education, team dynamics, and practice. ${ }^{15}$ These measurable outcomes ensure pharmacy students are prepared to provide patient-centered care and effectively work with other healthcare professionals. Much like clinical skills, interprofessional communication also requires particular attention to develop. In order to develop these skills, it is important to provide students with education and training that promotes and increases student confidence when interacting in a team setting. Current available literature supports the use of simulation training to increase student confidence. In 2018, Fusco and Foltz-Ramos ${ }^{16}$ evaluated changes in pharmacy and nursing student confidence following a highfidelity simulation experience. Median score increases were observed for all Student Perceptions of Interprofessional Clinical Education-Revised (SPICE-R) items $(p<0.01)$ for pharmacy students and nine of ten SPICE-R items $(p<0.01)$ for nursing students, indicating increased student perceptions to interprofessional care. While changes in confidence were not statistically significant between the pre-lecture and post-simulation surveys, they elucidated that this simulation training trended towards increased student confidence, with nearly a $30 \%$ positive growth in confidence scores. However, in order for students to be competent members of a

Table 3

Student evaluations of simulation.

\begin{tabular}{|c|c|c|}
\hline & \multicolumn{2}{|c|}{ Second-year pharmacy graduate students $(n=19)$} \\
\hline & Post-simulation median & $\begin{array}{l}\text { Percent "agree" or "strongly } \\
\text { agree" }\end{array}$ \\
\hline The simulation helped to reinforce what I previously learned about sepsis from class & 5 & 94.7 \\
\hline $\begin{array}{l}\text { This simulation made me more confident in my ability to identify and manage patients with } \\
\text { sepsis }\end{array}$ & 4 & 84.2 \\
\hline I found the sepsis lecture to be more valuable than the sepsis simulation & 3 & 26.3 \\
\hline $\begin{array}{l}\text { I believe that a combination of a lecture plus a simulation is the best way to learn about the topic } \\
\text { of sepsis }\end{array}$ & 4 & 94.7 \\
\hline This simulation helped me to develop my critical thinking skills & 4 & 94.7 \\
\hline This simulation will be helpful to me in my future experiences & 4 & 100 \\
\hline $\begin{array}{l}\text { This simulation helped improve my knowledge of what a pharmacist does as part of an } \\
\text { interdisciplinary medical team }\end{array}$ & 4 & 100 \\
\hline This simulation helped me to improve my interdisciplinary communication skills & 4 & 84.2 \\
\hline $\begin{array}{l}\text { This simulation helped me to improve my confidence in interacting with others as part of a } \\
\text { medical team }\end{array}$ & 4 & 94.7 \\
\hline
\end{tabular}

Questions answered on 5-point Likert scale: $5=$ strongly agree, $4=$ agree, $3=$ neutral, $2=$ disagree, $1=$ strongly disagree. 
patient care team, it is essential that they have not only confidence but also a strong knowledge base regarding various topics and disease states.

To our knowledge, no previous studies have evaluated the impact of simulated rounds on changes in sepsis knowledge. Although previous studies have indicated that simulation exercises increase knowledge and skills, ${ }^{9-12,17-20}$ our students did not show a statistically significant change in sepsis knowledge between the didactic lecture and simulation. This finding may be due to significant changes already being observed between the pre- and post-didactic lecture surveys as well as small sample sizes. Despite there not being any statistically significant changes in knowledge between post-lecture and post-simulation, a large proportion of students either strongly agreed or agreed that the combination of a lecture plus a simulation reinforced what they learned $(94.7 \% ; n=18)$. Students also believed that the combination of a lecture plus a simulation was the best way to learn about sepsis $(94.7 \% ; n=18)$. Also, students believed that the simulation enhanced their critical thinking skills (94.7\%). Interestingly, one sepsis knowledge domain displayed a numerical decrease in performance following the simulation when compared to the post-didactic lecture. This may have been a result of possible variances in team discussions that occurred during the mock rounding experience and the debriefing session.

Some design constraints may limit the validity of this study's findings. Since this study was completed at a single center, the generalizability of this study may be limited. Also, the sample size was small due to the nature of class sizes at the academic institution. While we did seek an internal review of our surveys before distribution, we did not seek external validation due to time constraints. Although improving communication is certainly a focus of this activity, the surveys were only designed to measure student perceptions of their ability to communicate in an interprofessional environment. The use of objective measurements related to changes in communication skills would be preferred. It would have been ideal to follow the same cohort over time to observe changes.

Ideally, the sepsis simulation activity would also have consisted of true interdisciplinary teamwork. Literature has demonstrated that students exposed to interprofessional education show improved communication, increased trust and mutual respect, a better understanding of roles and responsibilities, and raised job satisfaction. ${ }^{21}$ For the duration of this activity's existence, pharmacy faculty, residents, and APPE students have played the roles of physicians, medical residents, and pharmacy preceptors. In a study completed by Bell et al., ${ }^{22}$ authors found that $80 \%$ of learners felt that role-play with another clinician would not have been as valuable as with the use of actors. This simulation could likely be improved through the inclusion of non-faculty or non-resident actors. The long-term goal of this project is to develop the exercise into a true interprofessional activity by including healthcare professionals and students from other disciplines as both actors and participants, respectively. We believe that this activity has the potential to influence the development of students in all four Interprofessional Education Collaborative Core Competencies. ${ }^{23}$ In the future, we plan to modify this simulation to measure these competencies once it has been converted to a true interprofessional experience.

\section{Summary}

This simulation revealed improvements in student perceptions of self-confidence and the ability to work alongside other healthcare professionals. However, the simulation did not directly impact sepsis knowledge when compared to lecture alone. Future directions will explore methods to improve overall knowledge gains between the sepsis lecture and simulation. Incorporating other medical professionals and healthcare students into this simulation may provide more realism and allow for a more comprehensive investigation of changes in interprofessional attitudes.

\section{Disclosure(s)}

The authors of this study wish to acknowledge that a grant was provided by the Cedarville University School of Pharmacy for the completion of this research. This funding source had no role in study design or in the decision to submit this manuscript for publication.

\section{Declaration of Competing Interest}

The authors report no conflict of interest.

\section{References}

1. Vyas D, Mcculloh R, Dyer C, Gregory G, Higbee D. An interprofessional course using human patient simulation to teach patient safety and teamwork skills. Am $J$ Pharm Educ. 2012;76(4) https://doi.org/10.5688/ajpe76471.

2. Koo L, Layson-wolf C, Brandt N, et al. Qualitative evaluation of a standardized patient clinical simulation for nurse practitioner and pharmacy students. Nurse Educ Pract. 2014;14(6):740-746.

3. Keller KB, Eggenberger TL, Belkowitz J, Sarsekeyeva M, Zito AR. Implementing successful interprofessional communication opportunities in healthcare education: a qualitative analysis. Int J Med Educ. 2013;4:253-259.

4. Fleischmann C, Thomas-Rueddel DO, Hartmann M, et al. Hospital incidence and mortality rates of sepsis. Dtsch Arztebl Int. 2016;113(10):159-166.

5. Singer M, Deutschman CS, Seymour CW, et al. The third international consensus definitions for sepsis and septic shock (sepsis-3). JAMA. 2016;315(8):801-810.

6. Williams MD, Braun LA, Cooper LM, et al. Hospitalized cancer patients with severe sepsis: analysis of incidence, mortality, and associated costs of Care. Crit Care. 2004;8(5):291-298.

7. Torio CM, Andrews RM. National inpatient hospital costs: The most expensive conditions by payer, 2011. HCUP Statistical Brief \#160. Agency for Healthcare Research and Quality, Rockville, MD. Published August 2013. http://www.hcup-us.ahrq.gov/reports/statbriefs/sb160.pdf. Accessed 19 May 2019. 
8. Shrader S, McRae L, King IV WM, Kern D. A simulated interprofessional rounding experience in a clinical assessment course. Am J Pharm Educ. 2011;75(4) https:// doi.org/10.5688/ajpe75461.

9. Bingham AL, Sen S, Finn LA, Cawley MJ. Retention of advanced cardiac life support knowledge and skills following high-fidelity mannequin simulation training. Am J Pharm Educ. 2015;79(1) https://doi.org/10.5688/ajpe79112.

10. Serag-Bolos ES, Chudow M, Perkins J, Patel RV. Enhancing student knowledge through a comprehensive oncology simulation. Am J Pharm Educ. 2018;82(3) https://doi.org/10.5688/ajpe6245.

11. Serag-Bolos ES, Miranda AC, Gelot SR, Dharia SP, Shaeer KM. Assessing students' knowledge regarding the roles and responsibilities of a pharmacist with focus on care transitions through simulation. Curr Pharm Teach Learn. 2017;9(4):616-625.

12. Frenzel JE, Skoy ET, Eukel HN. Use of simulations to improve pharmacy students' knowledge, skills, and attitudes about medication errors and patient safety. Am $J$ Pharm Educ. 2018;82(8) https://doi.org/10.5688/ajpe6644.

13. Qualtrics [computer program]. Version. Provo, UT: Qualtrics Labs, Inc; 2019.

14. IBM SPSS Statistics for Windows [computer program]. Version 25.0. Armonk, NY: IBM Corp; 2017.

15. Accreditation Standards and Key Elements for the Professional Program in Pharmacy Leading to the Doctor of Pharmacy Degree ("Standards 2016"). Accreditation Council for Pharmacy Education. https://www.acpe-accredit.org/pdf/Standards2016FINAL.pdf. Published February 2015. Accessed 19 May 2019.

16. Fusco NM, Foltz-Ramos K. Measuring changes in pharmacy and nursing students' perceptions following an interprofessional high-fidelity simulation experience. $J$ Interprof Care. 2018;32(5):648-652.

17. Maxwell WD, Mohorn PL, Haney JS, et al. Impact of an advanced cardiac life support simulation laboratory experience on pharmacy student confidence and knowledge. Am J Pharm Educ. 2016;80(8) https://doi.org/10.5688/ajpe808140.

18. Branch C. Pharmacy students' learning and satisfaction with high-fidelity simulation to teach drug-induced dyspepsia. Am $J$ Pharm Educ. 2013;77(2) https://doi. org/10.5688/ajpe77230.

19. Lee Chin K, Ling Yap Y, Leng Lee W, Chang Soh Y. Comparing effectiveness of high-fidelity human patient simulation vs case-based learning in pharmacy education. Am J Pharm Educ. 2014;78(8) https://doi.org/10.5688/ajpe788153.

20. Smithburger PL, Kane-Gill SL, Ruby CM, Seybert AL. Comparing effectiveness of 3 learning strategies: simulation-based learning, problem-based learning, and standardized patients. Simul Healthc. 2012;7(3):141-146.

21. Homeyer S, Hoffmann W, Hingst P, Oppermann RF, Dreier-Wolfgramm A. Effects of interprofessional education for medical and nursing students: enablers, barriers and expectations for optimizing future interprofessional collaboration - a qualitative study. BMC Nurs. 2018;17. https://doi.org/10.1186/s12912-0180279-x.

22. Bell SK, Pascucci R, Fancy K, Coleman K, Zurakowski D, Meyer EC. The educational value of improvisational actors to teach communication and relational skills: perspectives of interprofessional learners, faculty, and actors. Patient Educ Couns. 2014;96(3):381-388.

23. Core Competencies for Interprofessional Collaborative Practice: 2016 Update. Interprofessional Education Collaborative. https://nebula.wsimg.com/ 2f68a39520b03336b41038c370497473? AccessKeyId=DC06780E69ED19E2B3A5\&disposition=0\&alloworigin=1. Published 2016. Accessed 19 May 2019. 